\title{
PROTÓTIPO DE FILTRAÇÃO APLICADO NA DEIONIZAÇÃO DA ÁGUA UTILIZANDO RESINA MISTA
}

\section{ARTIGO ORIGINAL}

BORGONOVI, Steven de Andrade 1, IBARRA, Gabrielle Amarilha 2, NECO, Gabriel Conforti Papa ${ }^{3}$, RODRIGUES, Rayane Vieira ${ }^{4}$, BARBOSA, Hueberton 5, PÁDUA, Aryston Vinicius Queiroz de Almeida ${ }^{6}$, SANTOS, Alexsander Saves dos ${ }^{7}$

BORGONOVI, Steven de Andrade. Et al. Protótipo de filtração aplicado na deionização da água utilizando resina mista. Revista Científica Multidisciplinar Núcleo do Conhecimento. Ano 06, Ed. 05, Vol. 14, pp. 61-72. Maio de 2021. ISSN: 2448-0959, Link de acesso: https://www.nucleodoconhecimento.com.br/engenhariaquimica/deionizacao-da-agua,

DOI: 10.32749/nucleodoconhecimento.com.br/engenharia-quimica/deionizacao-da-agua

\section{RESUMO}

Nesse trabalho foi projetado, construído e testado um protótipo de filtro deionizador para desmineralização de água bruta. O protótipo possui corpo principal de acrílico, com etapas de carvão, areia, pedra e resinas catiônica e aniônica, com uma base de madeira e um recipiente para coleta da água deionizada. Foi realizado o teste com água bruta, tendo esta, uma condutividade de 144,8-10-6 $\mu \mathrm{s} / \mathrm{cm}$ antes da filtragem, e

\footnotetext{
${ }^{1}$ Acadêmico em Engenharia Química.

2 Acadêmico em Engenharia Química.

${ }^{3}$ Acadêmico em Engenharia Química.

${ }^{4}$ Acadêmico em Engenharia Química.

${ }^{5}$ Acadêmico em Engenharia Química.

${ }^{6}$ Acadêmico em Engenharia Química.

${ }^{7}$ Orientador. Mestrado em Ciências Ambientais.
}

RC: 86629

Disponível em: https://www.nucleodoconhecimento.com.br/engenharia-quimica/deionizacaoda-agua 
posteriormente de 20,15·10-6 $\mu \mathrm{s} / \mathrm{cm}$, mostrando então uma eficiência considerável do sistema. O protótipo apresentou resultados satisfatórios e atendeu ao seu propósito de criação, baseando-se em SANEPAR (2013), onde para soluções com condutividade intermediaria tal como água mineralizada, potável e águas residuais, a faixa é de 10·10-6 $\mu \mathrm{s} / \mathrm{cm}$ até $2000 \cdot 10-6 \mu \mathrm{s} / \mathrm{cm}$.

Palavras-chave: Baixo custo, Filtração, Deionizador, Água.

\section{INTRODUÇÃO}

Segundo Teruya (2012), filtração é uma técnica experimental de divisão de mesclas heterogêneas compostas de um estado sólido e um estado fluído, via de regra, um líquido. É abundantemente utilizada não só para extinguir partículas sólidas do estado fluído, mas também para segregar um sólido disperso ou retido num líquido. $O$ processo de filtração pode ser usado, não apenas em escala de laboratório, mas também em escala industrial.

Procede tais técnicas de filtração: a filtração simples, também conhecida como comum e a filtração a vácuo.

Nas palavras de Salvador e Usberco (2006), no processo de filtração simples, realizado em laboratório, utiliza-se um papel de filtro, de formato circular, que é dobrado ao meio duas vezes, de modo a ser dividido em quatro partes. Este papel aumenta a área de superfície de filtração, agilizando o procedimento. Caso a parte de maior relevância seja o resíduo sólido que se encontra retido no papel de filtro, existe a possibilidade de dobrá-lo ainda mais. Este papel de filtro é então colocado em um funil analítico e com o auxílio de uma baqueta de vidro, a mistura é transferida. Ao passo que as partículas sólidas ficam retidas no filtro, o líquido que passa pelos poros é coletado em outro recipiente. Já no processo de filtração a vácuo, a diferença se encontra na aplicação do vácuo (baixa pressão) dentro do recipiente, o qual irá coletar

RC: 86629

Disponível em: https://www.nucleodoconhecimento.com.br/engenharia-quimica/deionizacaoda-agua 
a solução filtrada. Neste processo, devido a aplicação do vácuo, a ocorrência da sucção agiliza o procedimento.

Entre os processos de filtração é possível também a aplicação de um filtro para desmineralização ou deionização obtendo água pura. O processo desmineralizador da água é constituído na retirada dos íons (ânion e cátions) presentes na mesma, sendo assim, o procedimento é comumente denominado de deionização. Dispõe dos mesmos benefícios e aspectos da água destilada, no entanto são obtidas por outros procedimentos. Esse processo acontece com a permanência de uma resina de troca iônica composta por produtos sintéticos, anexada no final do filtro, que possibilita a purificação da água a nível químico, com transição de íons contaminantes por íons inertes à solução.

Quando colocadas na água, as resinas de troca iônica poderão liberar íons sódio ou hidrogênio (resinas catiônicas) ou hidroxila (resinas aniônicas) e captar desta mesma água, respectivamente, cátions e ânions, responsáveis por seu teor de sólidos dissolvidos, indesejáveis a muitos processos industriais (SAKAI, 2012).

A mais importante mudança da água desmineralizada para a destilada é que o primeiro procedimento de purificação não faz uso de energia. Somente são utilizadas resinas específicas que realizam uma troca iônica, surgindo assim a água purificada. Além desta há também o procedimento através de osmose reversa, no qual a filtragem não faz uso de produtos químicos e a mesma é um processo mecânico (AFONSO, 2015).

O mais importante é a qualidade final da água desmineralizada produzida e onde ela será utilizada. No caso de usinas, a água será muito utilizada em lavagens de caldeiras, enquanto em laboratórios, se aplica para lavagem final de vidrarias.

O objetivo desse trabalho foi construir um filtro deionizador utilizando resina mista e outros filtrantes e avaliar seu funcionamento para filtragem de água para consumo industrial e laboratorial.

RC: 86629

Disponível em: https://www.nucleodoconhecimento.com.br/engenharia-quimica/deionizacaoda-agua 


\section{MATERIAL E MÉTODOS}

O presente projeto foi realizado no período de Agosto à Dezembro de 2019 na Universidade Brasil, localizada na Estrada Projetada F-1 s/n Fazenda Santa Rita, no Município de Fernandópolis-SP.

A primeira etapa foi a escolha e desenho técnico do modelo do equipamento conforme Figura $1 \mathrm{com}$ escala em $\mathrm{mm}$, levando em consideração a melhor produção e rendimento na filtração. $O$ produto final foi definido em $30 \mathrm{~cm}$ para o comprimento da coluna e largura de $10 \mathrm{~cm}$.

Figura 1 - Desenho técnico do projeto.

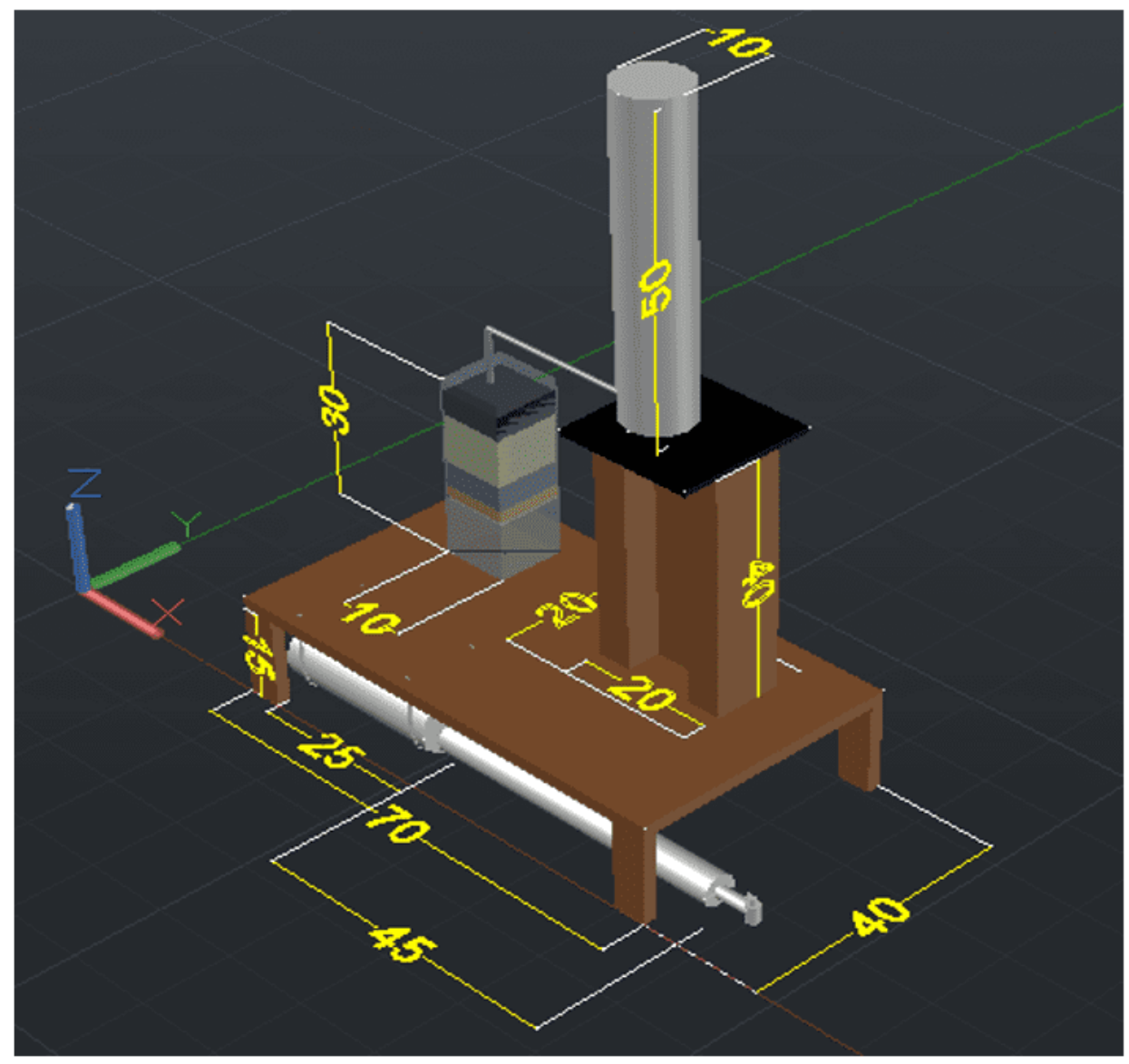

Fonte: Os autores.

RC: 86629

Disponível em: https://www.nucleodoconhecimento.com.br/engenharia-quimica/deionizacaoda-agua 
Em seguida, foi realizada a aquisição dos materiais elencados na Tabela 1. Alguns materiais como a malha da peneira, canos e plataforma de madeira foram doações da Usina Bpbunge da cidade de Ouroeste/SP e da Madeireira Lourenção localizada na cidade de Fernandópolis/SP. O intuito foi utilizar materiais de baixo custo e reaproveitáveis.

Tabela 1 - Materiais e valores.

\begin{tabular}{|c|c|c|c|}
\hline Materiais & Quantidade & $\begin{array}{l}\text { Valor Unitário } \\
\text { (R\$) }\end{array}$ & $\begin{array}{l}\text { Valor Total } \\
\text { (R\$) }\end{array}$ \\
\hline Filtro acrílico $10 \times 30 \mathrm{~cm}$ & 1 & 65,00 & 65,00 \\
\hline Torneira $3 / 4$ & 2 & 4,50 & 9,00 \\
\hline Tabua madeira $70 \times 40 \mathrm{~cm}$ & 1 & 0,0 & 0,0 \\
\hline Mangueira borracha $3 / 4$ & $1 \mathrm{~m}$ & 2,70 & 2,70 \\
\hline Mangueira borracha $1 / 2$ & $1 \mathrm{~m}$ & 2,30 & 2,30 \\
\hline Cano pvc 100mm (reservatório) & $20 \mathrm{~cm}$ & 8,50 & 8,50 \\
\hline Cano pvc $100 \mathrm{~mm}$ & $30 \mathrm{~cm}$ & 10,00 & 10,00 \\
\hline Cano pvc 50mm & $45 \mathrm{~cm}$ & 8,00 & 8,00 \\
\hline Abraçadeira $3 / 4$ em U & 2 & 0,55 & 1,10 \\
\hline Abraçadeira $1 / 2$ em U & 2 & 0,55 & 1,10 \\
\hline Serra & 1 & 0,0 & 0,0 \\
\hline Parafuso & 8 & 0,10 & 0,80 \\
\hline Plataforma de madeira $70 \times 40 \mathrm{~cm}$ & 1 & 0 & 0 \\
\hline Estilete & 1 & 0,0 & 0,0 \\
\hline Cola silicone & 1 & 15,00 & 15,00 \\
\hline $\begin{array}{l}\text { Suporte de madeira caseiro } \\
40 \times 20 \mathrm{~cm}\end{array}$ & 1 & 0,00 & 0,00 \\
\hline Tampão pvc 100mm & 4 & 2,00 & 8,00 \\
\hline Malha de peneira $10 \times 10 \mathrm{~cm}$ & 1 & 0,0 & 0,0 \\
\hline Pedra & $300 \mathrm{~g}$ & 2,00 & 2,00 \\
\hline
\end{tabular}

RC: 86629

Disponível em: https://www.nucleodoconhecimento.com.br/engenharia-quimica/deionizacaoda-agua 


\begin{tabular}{|l|l|l|l|}
\hline Areia & $500 \mathrm{~g}$ & 3,00 & 3,00 \\
\hline Cano pvc 50mm & 1 & 8,00 & 8,00 \\
\hline Carvão ativado & $200 \mathrm{~g}$ & 35,00 & 35,00 \\
\hline Resina iônica & $500 \mathrm{~g}$ & 60,80 & 60,80 \\
\hline Total & - & - & $\mathbf{2 4 0 , 3 0}$ \\
\hline
\end{tabular}

Fonte: Os autores.

A próxima etapa foi à montagem do equipamento externo com as plataformas de madeira, na sequência, realizou-se duas perfurações de $13 \mathrm{~mm}$, na parte superior (entrada da água bruta) e na inferior (saída da água deionizada), no filtro acrílico que

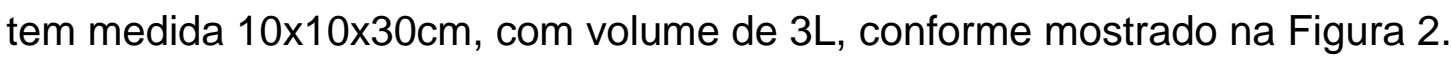

Figura 2 - Montagem parte externa.

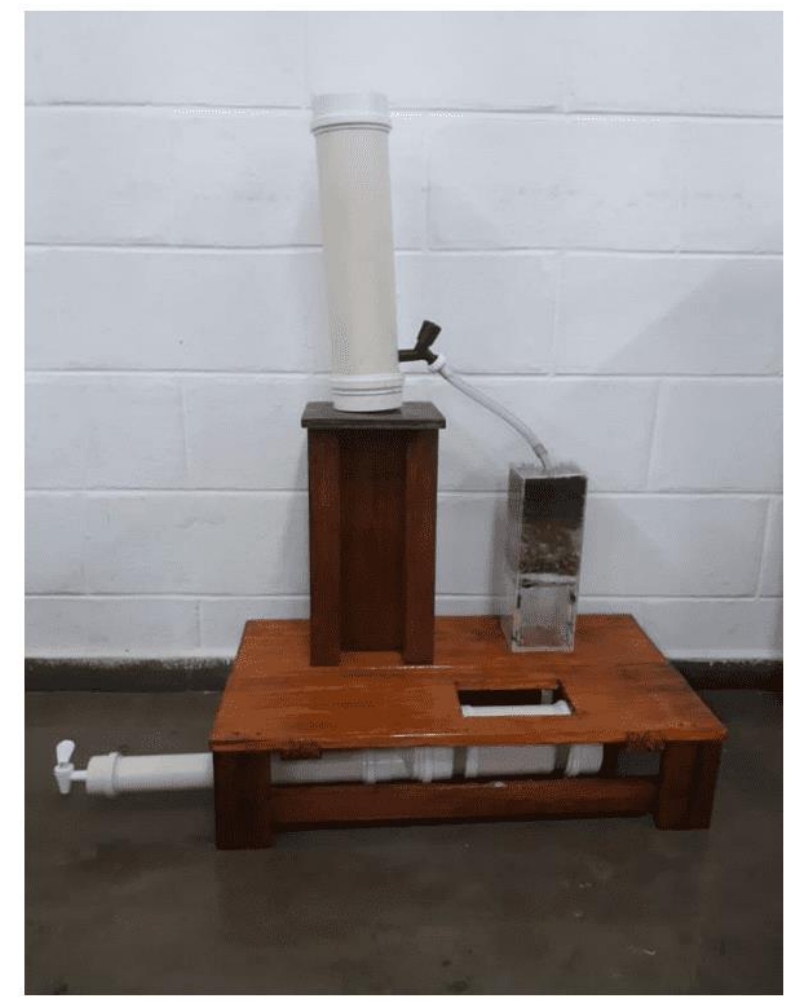

Fonte: Os autores.

RC: 86629

Disponível em: https://www.nucleodoconhecimento.com.br/engenharia-quimica/deionizacaoda-agua 
$\mathrm{Na}$ sequência, foi realizada a montagem da parte interna do filtro, onde efetuou-se o processo de filtragem com o propósito de retirar todos os minérios e sais contidos na água bruta, apresentado na Figura 3.

Figura 3 - Montagem parte interna.

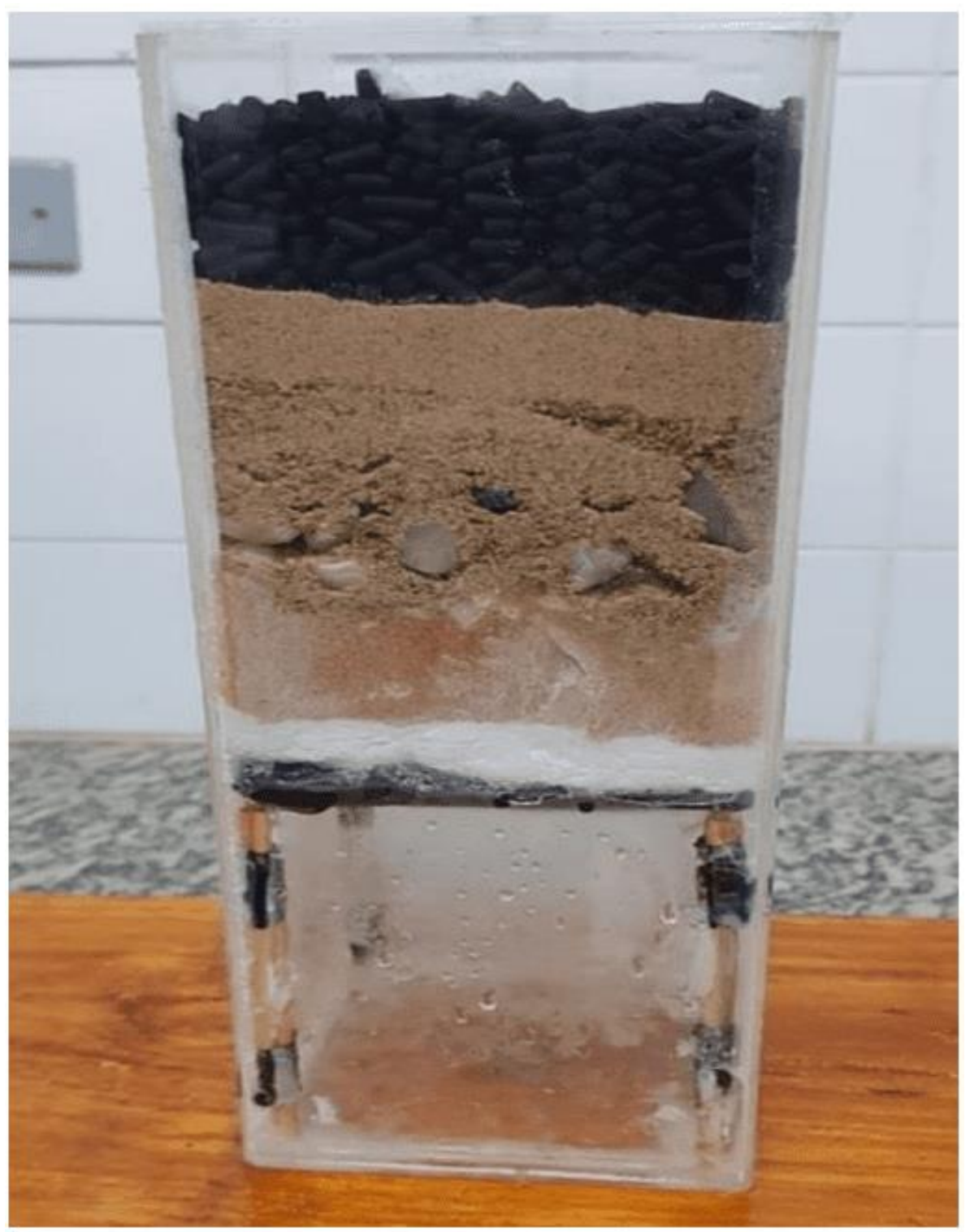

Fonte: Os autores.

RC: 86629

Disponível em: https://www.nucleodoconhecimento.com.br/engenharia-quimica/deionizacaoda-agua 
A etapa da montagem interna, segue a sequência de um filtro usual, iniciando com o carvão ativado que é um dos adsorventes mais importantes, do ponto de vista industrial, sendo utilizado para separação e purificação de misturas em fase gasosa e líquida, em seguida os filtros de areia e cascalho retiram turbidez, particulados e pequena quantidade de material emulsionado na forma coloidal ou emulsão, melhorando a cor e o sabor, posteriormente introduziu-se a resina mista que é composta de 50\% resina catiônica e 50\% resina aniônica, sendo esta, desenvolvida especialmente para tratamento de água em indústrias e laboratórios, são utilizadas para remoção de íons da água, após inclui-se uma camada de algodão que ajuda na remoção de sólidos da água, devido à alta superfície de contato, consequência das dimensões micrométricas dos fios e finalizou-se com uma malha de filtro para garantir uma alta eficiência do processo de filtragem.

Após o processo, a água deionizada é destinada para o próximo recipiente, sendo conduzida em tubulação de borracha, gravitacionalmente, sendo recebida em um reservatório de cano com volume de $2,45 \mathrm{~L}$, fazendo assim a estocagem do produto, sendo representado pela Figura 4.

Figura 4 - Processo de estocagem.

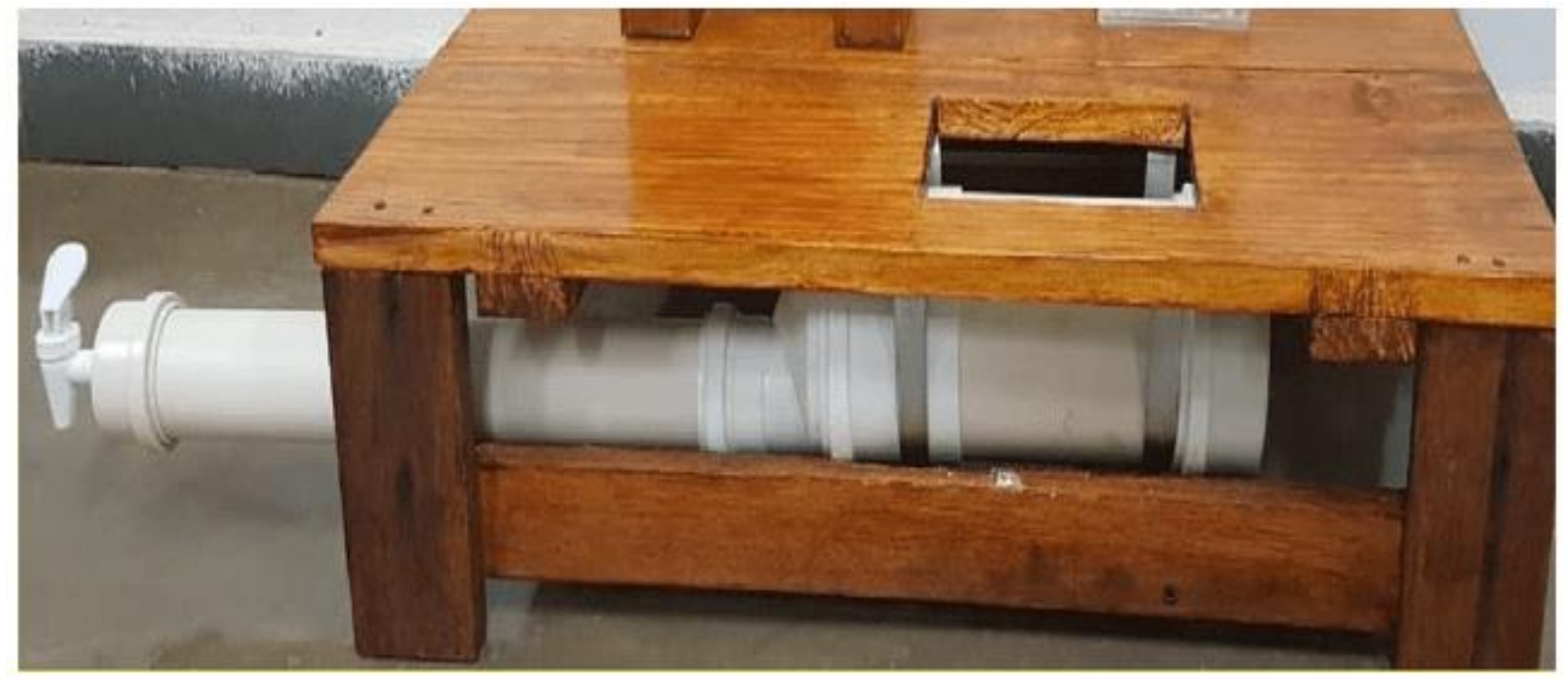

Fonte: Os autores.

RC: 86629

Disponível em: https://www.nucleodoconhecimento.com.br/engenharia-quimica/deionizacaoda-agua 


\section{RESULTADOS E DISCUSSÃO}

Realizou-se análises de condutividade antes e depois de cada filtragem. Os resultados foram tabulados e apresentados na Tabela 2:

Tabela 2 - Valores de condutividade.

\begin{tabular}{|l|l|l|}
\hline Testes & Condutividade da água bruta & Condutividade da água deionizada \\
\hline 1 & 144.8 & 20,15 \\
\hline 2 & 164.3 & 17,56 \\
\hline 3 & 164.3 & 16,21 \\
\hline 4 & 164,3 & 16,14 \\
\hline 5 & 166.1 & 17,25 \\
\hline
\end{tabular}

Fonte: Os autores

Observa-se uma redução na taxa de condutividade equivalente a $70 \%$. O processo de troca iônica se deu, devido o emprego de resinas sintéticas, onde as mesmas retêm os sais dissolvidos na água por meio de uma reação química, liberando íons equivalentes para a solução. A água bruta a ser desmineralizada deve ser submetida a uma pré-filtragem para remoção dos sólidos em suspensão: barro, areia e outros, incluindo o cloro, sendo este, removido no inicio da filtragem, devido a presença do carvão atividado. Segundo Saves (2018, apud SANTOS, 2019)

É natural a saturação da resina conforme o tempo de uso, assim, é necessário que a água produzida seja monitorada frequentemente com o auxílio de um condutivimetro, permitindo determinar quando a mesma deverá ser substituída. O nível máximo de condutividade que determinará quando a resina deverá ser trocada dependerá do uso a que se destina a água purificada, sendo estabelecida pelo usuário para cada aplicação. Valores de referência são apresentados na Quadro 1.

RC: 86629

Disponível em: https://www.nucleodoconhecimento.com.br/engenharia-quimica/deionizacaoda-agua 
Quadro 1 - Valores de referência de condutividade.

\begin{tabular}{|l|l|}
\hline Aplicação & Faixa \\
\hline $\begin{array}{l}\text { Para soluções com baixa condutividade de tal como água } \\
\text { destilada, deionizada ou ultra- }\end{array}$ & $0,5 \mu \mathrm{s}$ até $400 \mu \mathrm{s}$ \\
\hline pura. & \\
\hline $\begin{array}{l}\text { Para soluções com condutividade intermediaria tal como água } \\
\text { mineralizada, potável e água }\end{array}$ & $10 \mu \mathrm{s}$ até $2000 \mu \mathrm{s}$ \\
\hline $\begin{array}{l}\text { residuais. } \\
\text { Para soluções com boa condutividade tal que água do mar, } \\
\text { ácidos, bases e sais diluídos, }\end{array}$ & $1000 \mu \mathrm{s} \quad$ até \\
\hline soluções fisiológicas. & \\
\hline
\end{tabular}

Fonte: SANEPAR, 2013.

Foram calculados a vazão do filtro utilizando a Equação 1:

$$
\begin{gathered}
-Q={ }^{V} \\
T
\end{gathered}
$$

Equação 1 :

onde $Q$ é a vazão, V é o volume, e t é o tempo.

$A$ vazão do filtro foi realizada, em que $t=49.15 \mathrm{~s}$ e $V=0,003 \mathrm{~m}^{3}$ e obteve-se $Q=6,1 \times 10-5$ $\mathrm{m} 3 / \mathrm{s}$. Foi calculado o volume ocupado no filtro pelos materiais utilizando a Equação 2:

RC: 86629

Disponível em: https://www.nucleodoconhecimento.com.br/engenharia-quimica/deionizacaoda-agua 
Equação 2: $\quad V=A \cdot h$

Onde $\mathrm{V}$ é o volume prenchido do filtro, $\mathrm{A}$ é a area do filtro e h é a altura ocupada pelos componentes do filtro. $O$ volume prenchido foi calculado tendo $A=0,01 \mathrm{~m}^{2}$ e $h=$ $0,019 \mathrm{~m}$.

$\mathrm{V}=0,00195 \mathrm{~m} 3$.

Tabela 3 - Resultado de Cálculos

\begin{tabular}{|l|l|}
\hline Rendimento & $\cong 72 \%$ \\
\hline Volume do material contido no filtro & $0,00195 \mathrm{~m} 3$ \\
\hline Volume do filtro & $0,003 \mathrm{~m}^{3}$ \\
\hline Vazão Volumetrica & $6,1 \times 10-5 \mathrm{~m} 3 / \mathrm{s}$. \\
\hline
\end{tabular}

Fonte: Os autores.

\section{CONCLUSÕES}

Conclui-se que o rendimento do protótipo foi satisfatório, quando comparado com os resultados publicados por SANEPAR (2013). A variação dos valores obtidos no final de cada amostra, depende da água utilizada na filtração, entretanto, os resultados obtidos foram lineares durante todos os testes, mostrando assim a eficiência do sistema, uma vez que o processo pode ser realizado diversas vezes sem necessidade de reposição dos materiais.

Pressupõe-se que é possível aumentar a eficiência do protótipo, se alterado a extensão da coluna de resina, desde que se mantenha a vazão. A quantidade de resina/ tempo de retenção, são fatores cruciais para o desempenho do protótipo.

Em uma possível replicagem do filtro, diminuir o espaço vazio deixado no final da coluna, pois o mesmo serve apenas para evitar a pressão inversa.

RC: 86629

Disponível em: https://www.nucleodoconhecimento.com.br/engenharia-quimica/deionizacaoda-agua 


\section{REFERÊNCIAS}

AFONSO, Julio Carlos. Separação sólido-líquido: Centrífugas e papeis filtro. Química Nova, volume nํ38, no.05. São Paulo, Junho de 2015

SAKAI, Suzana. Resinas trocadoras de ĺons, soluções a favor do tratamento de água e efluentes. Revista TAE, São Paulo, edição № 9 - outubro/novembro de 2012 - Ano 2.

SALVADOR, Edgard e USBERCO, João. Química, volume único. 1ª edição. São Paulo-SP: Editora Saraiva, 2006. 672 p.

SANEPAR. Companhia de Saneamento do Paraná, 2013. Disponível em: <https://site.sanepar.com.br/>

TERUYA, Leila Cardoso. Filtração Simples. LABIQ - Laboratório de Química e Bioquímica. Disponível em: $<$ http://labiq.iq.usp.br/paginas_view.php?idPagina=4\&idTopico=68\#.Yls6H7VKjDc> Acesso em: 12 de outubro 2019.

Enviado: Fevereiro, 2021.

Aprovado: Maio, 2021.

RC: 86629

Disponível em: https://www.nucleodoconhecimento.com.br/engenharia-quimica/deionizacaoda-agua 